\title{
Estrogen and raloxifene induce apoptosis by activating p38 mitogen-activated protein kinase cascade in synthetic vascular smooth muscle cells
}

\author{
A Mori-Abe, S Tsutsumi, K Takahashi, M Toya, M Yoshida, B Du, \\ J Kawagoe, K Nakahara, T Takahashi, M Ohmichi and H Kurachi \\ Department of Obstetrics and Gynecology, Yamagata University, School of Medicine, 2-2-2 lidanishi, Yamagata 990-9585, Japan \\ (Requests for offprints should be addressed to M Ohmichi; Email: masa@med.id.yamagata-u.ac.jp)
}

\begin{abstract}
Proliferation of vascular smooth muscle cells (VSMC) plays a major role as an initiating event of atherosclerosis. Although estrogen directly inhibits the proliferation of VSMC, the mechanism has not been firmly established. In addition, the effect of raloxifene on VSMC remains unknown. 17 $\beta$-Estradiol $\left(\mathrm{E}_{2}\right)$ and raloxifene significantly inhibited the growth of VSMC under growth-stimulated conditions. Since mitogen-activated protein (MAP) kinases have been implicated in VSMC proliferation, the role of MAP kinases in both the $\mathrm{E}_{2^{-}}$and raloxifeneinduced growth inhibition of VSMC was studied. Both $\mathrm{E}_{2}$ and raloxifene caused rapid, transient phosphorylation and activation of $\mathrm{p} 38$ that was not affected by actinomycin D and was blocked by ICI 182,780. In contrast with p38 phosphorylation, extracellular signal-regulated protein kinase (ERK) phosphorylation was significantly inhibited and c-Jun N-terminal kinase (JNK) phosphorylation was
\end{abstract}

not changed by $E_{2}$. Because VSMC expressed both estrogen receptor (ER) $\alpha$ and $\operatorname{ER} \beta$, it is not known which of them mediates the $\mathrm{E}_{2}$-induced phosphorylation of $\mathrm{p} 38$. Although $\mathrm{E}_{2}$ did not affect the $\mathrm{p} 38$ phosphorylation in $\mathrm{A} 10$ smooth muscle cells, which express ER $\beta$ but not ER $\alpha$, transfection of ER $\alpha$ expression vector into A10 cells rendered them susceptible to induction of p38 phosphorylation by $E_{2}$. We then examined whether $E_{2}$ and raloxifene induce apoptosis through a p38 cascade. Both $\mathrm{E}_{2}$ and raloxifene induced apoptosis under growthstimulated conditions. The p38 inhibitor SB 203580 completely blocked the $\mathrm{E}_{2}$-induced apoptosis. Our findings suggest that both $\mathrm{E}_{2}$ - and raloxifene-induced inhibition of VSMC growth is due to induction of apoptosis through a p38 cascade whose activation is mediated by $\mathrm{ER} \alpha$ via a nongenomic mechanism.

Journal of Endocrinology (2003) 178, 417-426

\section{Introduction}

Many epidemiological studies and basic studies have shown that estrogen has the significant function in the vasculature of preventing the primary development of cardiovascular disease in women (Stampfer et al. 1991, Mendelsohn \& Karas 1999). In the Women's Health Initiative's (WHI), a large prospective randomized controlled study, although women on combined estrogenprogestin had an increase in the relative risk of cardiovascular events, interim reports on women on estrogen alone did not show adverse effects on the risk of cardiovascular disease (Writing Group for the Women's Health Initiative Investigators 2002). Thus, the cardioprotective effect of estrogen itself was not ruled out by the results of the WHI study. It is possible that progestin has adverse effects on the cardiovascular system (Wakatsuki et al. 2001). Therefore, there is a need for an ideal estrogen analog that does not require the addition of progestin to protect the uterine endometrium. Raloxifene is a nonsteroidal benzothiophene that has been classified as a selective estrogen receptor modulator (SERM) based on the fact that it produces estrogen-agonistic effects on bone (Ross \& Glomset 1973) and lipid metabolism (Truss \& Beato 1993) and estrogen-antagonistic effects on uterine endometrium (Ross \& Glomset 1973) and breast tissue (Pietras \& Szego 1977, Falkenstein \& Wehling 2000). However, its ability to protect against cardiovascular disease has yet to be proven, and is now being tested in the RUTH (Raloxifene Use for The Heart) trial.

Pathological proliferation of vascular smooth muscle cells (VSMC) plays a major role in the development of atherosclerotic lesions (Kindy \& Sonenshein 1986). The growth of VSMC is stimulated by the presence of a high concentration of serum (10\% FBS) or platelet-derived growth factor (PDGF) (Nilsson et al. 1985), and this growth is accompanied by a change from the contractile to the synthetic phenotype of VSMC (Nilsson et al. 1985, 
Kindy \& Sonenshein 1986), and thus represents an atherosclerotic model in vitro.

In vertebrates, the actions of many stimuli resulting in proliferative or hypertropic growth converge on a set of cellular kinase cascades that are collectively called the mitogen-activated protein (MAP) kinase cascades (Force \& Bonventre 1998). These MAP kinases have been implicated in VSMC proliferation and hypertropy and in responses that are central to the pathophysiology of hypertension (Force \& Bonventre 1998). Dubey et al. (2000) reported that $17 \beta$-estradiol $\left(\mathrm{E}_{2}\right)$ inhibits the growth of VSMC partly by reducing extracellular signal-regulated protein kinase (ERK) 1/2 activity. We (Hisamoto et al. 2000) and other groups (Simoncini et al. 2000) also showed that estrogen induces the activation of endothelial nitric oxide synthase (eNOS) in a nongenomic manner in vascular endothelial cells. However, the range of the biological consequences of the signal transduction cascades activated in VSMC by estrogen in a nongenomic manner has not been defined.

Therefore, these considerations led us to examine whether there are other $\mathrm{E}_{2}$-induced signaling pathways involved in the inhibition of VSMC growth, and whether raloxifene, like estrogen, also inhibits VSMC growth, and the mechanism of the growth inhibition. We report here the novel observation that both $\mathrm{E}_{2}$ and raloxifene induce the phosphorylation and activation of $\mathrm{p} 38$, which is a member of the MAP kinase family, in VSMC. This signal transduction cascade substantially induces apoptosis under growth-stimulated conditions. These findings implicate the non-genomic actions of both $\mathrm{E}_{2}$ and raloxifene in the anti-atherogenic effects of the hormones.

\section{Materials and Methods}

\section{Materials}

$\mathrm{E}_{2}$ and actinomycin $\mathrm{D}$ were purchased from Sigma Chemical Co. (St. Louis, MO, USA). Raloxifene analog (LY 117018) was a kind gift from Eli Lilly Research Laboratories (Indianapolis, IN, USA). ICI 182,780 was obtained from Tocris (Ballwin, MO, USA). SB 203580 was obtained from CALBIOCHEM (La Jolla, CA, USA). Platelet-derived growth factor (PDGF)-BB was obtained from PeproTech (Rocky Hill, NJ, USA). The Cell Titer 96 AQueous One Solution Cell Proliferation Assay kit was obtained from Promega (Madison, WI, USA). Rabbit polyclonal anti-(phospho- and total) c-Jun N-terminal kinase (JNK), p38, and ERK1/2 antibodies, and a p38 activity assay kit including ATF-2 fusion protein and anti-phospho-ATF-2 antibody were obtained from New England Biolabs (Beverly, MA, USA). Rabbit polyclonal anti-estrogen receptor (ER) $\alpha$ antibody was obtained from Santa Cruz Biotechnology, Inc. (Santa Cruz, CA, USA). Human aortic smooth muscle cells (VSMC) were obtained from Clonetics (Walkersville, MD, USA). The A10 cell line, which was derived from the thoracic aorta of embryonic rats, was obtained from American Type Culture Collection (Rockville, MD, USA).

\section{Constructs}

The human ER $\alpha$ expression vector, pCMV-fER, was a kind gift from Dr D J Shapiro (University of Illinois, Urbana, IL, USA) (Zhang et al. 1999).

\section{Cell viability assays}

After $5 \cdot 0 \times 10^{3}$ cells were seeded per well in a 96-well plate, they were incubated for $24 \mathrm{~h}$ in Dulbecco's modified Eagle's medium (DMEM) with 10\% fetal bovine serum (FBS), and then starved in DMEM with $0 \cdot 4 \%$ FBS for $48 \mathrm{~h}$. Cell viability was assessed after a 48 -h incubation with $\mathrm{E}_{2}$ or raloxifene with or without a high concentration of serum (10\% FBS) or $25 \mathrm{ng} / \mathrm{ml}$ PDGF-BB. The number of surviving cells was measured by determination of the absorbance at $490 \mathrm{~nm}$ of the dissolved formazan product after addition of 3-(4,5-dimethylthiazol-2-yl)-5(3-carboxylmethoxyphenyl)-2-(4-sulfophenyl)-2H-tetrazolium inner salt (MTS) for $1 \mathrm{~h}$ as described previously (Hayakawa et al. 2000).

\section{Western blots}

Cells were washed with phosphate-buffered saline (PBS), and total cell lysates were prepared in lysis buffer $(20 \mathrm{mM}$ Tris ( $\mathrm{pH} 7 \cdot 4), 150 \mathrm{mM}$ EDTA, $1 \mathrm{mM}$ EGTA, 1\% Triton $\mathrm{X}-100, \quad 2.5 \mathrm{mM}$ sodium pyrophosphate, $1 \mathrm{mM} \quad \beta$ glycerolphosphate, $1 \mathrm{mM}$ sodium orthovanadate, $1 \mu \mathrm{g} / \mathrm{ml}$ leupeptin, and $1 \mathrm{mM}$ phenylmethylsulfonyl fluoride). Twenty micrograms cell lysates were analyzed by SDSPAGE followed by the chemiluminescence Western blotting method using the indicated antibodies, as described previously (Hayakawa et al. 2000).

\section{Assay of p38 activity}

Two hundred micrograms cell lysate were incubated with immobilized phospho-p38 monoclonal antibody. The immunoprecipitated products were resuspended in $50 \mu \mathrm{l}$ kinase buffer $\left(25 \mathrm{mM}\right.$ Tris, $\mathrm{pH} 7 \cdot 5,10 \mathrm{mM} \mathrm{MgCl}_{2}, 5 \mathrm{mM}$ $\beta$-glycerolphosphate, $0 \cdot 1 \mathrm{mM}$ sodium orthovanadate, and $2 \mathrm{mM}$ dithiothreitol) containing $200 \mu \mathrm{M}$ ATP and $2 \mu \mathrm{g}$ ATF-2 fusion protein. The kinase reaction was allowed to proceed at $30{ }^{\circ} \mathrm{C}$ for $30 \mathrm{~min}$ and stopped by the addition of sample buffer. Reaction products were resolved by SDSPAGE and then subjected to Western blotting with anti-phospho-ATF-2 antibody.

\section{Apoptosis assay}

Five thousand cells/well were placed into extracellular matrix-coated chamber slides in DMEM with $10 \%$ FBS, 
and then starved for $48 \mathrm{~h}$ in DMEM with $0 \cdot 4 \%$ FBS. After starvation, some cells were treated with various materials. Apoptosis was assessed by terminal deoxynucleotidyl transferase-mediated dUTP nick end-labeling (TUNEL) staining using an Apoptosis In Situ Detection kit (Wako, Osaka, Japan), and the cells undergoing programmed cell death were counted in five separate fields/experiment. Alternatively, cells were analyzed for apoptosis by flow cytometry (FACSCalibur, Becton Dickinson, Mountain View, CA, USA). Following the treatment described above, trypsin-detached VSMC were pooled and washed once with PBS and fixed in 70\% cold ethanol. After fixation, cells were stained with PBS, propidium iodide $(50 \mu \mathrm{g} / \mathrm{ml})$, RNase A $(50 \mu \mathrm{g} / \mathrm{ml}), 0 \cdot 1 \%$ Triton X-100 and $0 \cdot 1 \mathrm{mM}$ EDTA for $24 \mathrm{~h}$. The DNA content of VSMC was analyzed by flow cytometry using a FACSCalibur flow cytometer. At least 10000 events were analyzed, and the percentage of cells in the sub- $G_{1}$ population was calculated. Both types of apoptosis assays were repeated three times with consistent results.

\section{Reverse transcriptase-polymerase chain reaction (RT-PCR) experiments}

Total RNA was extracted from VSMC and A10 cells with Tri-Reagent (Molecular Research Center, Inc, Cincinnati, OH, USA) according to the manufacturer's instructions. Total RNA (5 $\mu \mathrm{g})$ was used as a template for first-strand synthesis. An RT-PCR kit obtained from TakaRa (Tokyo, Japan) was used according to the manufacturer's instructions. Primers were designed from published gene sequences. The sequences of the PCR primers were as follows: rat ER $\alpha$ : 5'AATTCTGACAATCGACGCC- $3^{\prime}$ and $5^{\prime}$-GTGCTTC AACATTCTCCCTCCTC- $3^{\prime}$; rat ER $\beta$ : $5^{\prime}$-TTCCC GGCAGCACCAGTAACC- $3^{\prime}$ and $5^{\prime}$-TCCCTCTTTG CG TTTGGACTA-3'; human ER $\alpha$ : 5'-GGCCAGT ACCAATGACAAGGGAAG- ${ }^{\prime}$ and $5^{\prime}$-CCAGCAAGC ATGTCGAAGATCTCC-3'; human ER $\beta$ : $5^{\prime}$-GTTGC GCCAGCCCTGTTAC- $3^{\prime}$ and $5^{\prime}$-CTCGTCGGCA CTTCTCTGTCTC-3'. To check cDNA integrity, fragments of glyceraldehyde-3-phosphate dehydrogenase $($ GAPDH $)$ were amplified in parallel. The amplification conditions consisted of 35 cycles of incubation at $94{ }^{\circ} \mathrm{C}$ for $1 \mathrm{~min}, 59^{\circ} \mathrm{C}$ for $1 \mathrm{~min}$, and $72{ }^{\circ} \mathrm{C}$ for $1 \mathrm{~min}$. PCR products were electrophoresed on a 1.5\% agarose gel and visualized by ethidium bromide staining under UV illumination.

\section{Assay of p38 phosphorylation using a transient expression system}

A10 cells cultured in 100-mm dishes were transfected with $1 \mu \mathrm{g}$ ER $\alpha$ expression vector (pCMV-fER) using Lipofectamine Plus as described previously (Hisamoto et al. 2000). Seventy-two hours after transfection, serum- deprived cells were incubated with $10^{-8} \mathrm{M} \mathrm{E}_{2}$ and cell lysates were analyzed by SDS-PAGE, followed by Western blotting using a specific antibody against phosphorylated p38.

\section{Statistics}

Statistical analysis was performed by Student's $t$-test, and $P<0.05$ was considered significant. Data are expressed as means \pm S.E.

\section{Results}

Effects of $E_{2}$ and raloxifene on cell growth of VSMC

We evaluated the effect of $\mathrm{E}_{2}$ on VSMC under growthstimulated and non-stimulated conditions. No growth inhibitory effect by estrogen at $10^{-10}$ to $10^{-7} \mathrm{M}$ was observed under quiescent conditions $(0 \cdot 4 \%$ FBS) (Fig. 1A). Treatment with 10\% FBS significantly stimulated the proliferation (by 1.53-fold) (Fig. 1B), as did treatment with 25 ng/ml PDGF-BB (by 1.33-fold) (Fig. 1C). Significant, dose-dependent growth inhibition by $\mathrm{E}_{2}$ under the growth-stimulated (10\% FBS) conditions was observed at concentrations of $10^{-9} \mathrm{M}$ to $10^{-7} \mathrm{M}$ (Fig. $1 \mathrm{~B}$ and $\mathrm{C}$ ). Raloxifene at $10^{-9} \mathrm{M}$ also caused a significant growth inhibition in cells treated with 10\% FBS (Fig. 1D). These data suggest that physiological concentrations of $\mathrm{E}_{2}$ and raloxifene inhibit the cell growth of VSMC with the synthetic phenotype.

Effect of $E_{2}$ and raloxifene on MAP kinase family members in VSMC

Since mitogen-activated protein (MAP) kinases have been implicated in VSMC proliferation, the role of MAP kinases in the $\mathrm{E}_{2^{-}}$and raloxifene-induced growth inhibition of VSMC was studied. To evaluate whether MAP kinases are activated by $\mathrm{E}_{2}$, cells were treated with $10^{-8} \mathrm{M}$ of $\mathrm{E}_{2}$ under growth-stimulated (10\% FBS) or unstimulated $(0 \cdot 4 \% \mathrm{FBS})$ conditions. Cell extracts were prepared and subjected to Western blot analysis using antibodies against the phosphorylated forms of various MAP kinase family members, namely ERK (p-ERK), JNK (p-JNK), and p38 (p-p38). As reported previously (Dubey et al. 2000), ERK phosphorylation was significantly inhibited by $\mathrm{E}_{2}$ in a dose-dependent manner under the growth-stimulated conditions (Fig. 2A, upper and middle panels). Although JNK was phosphorylated in response to UV (30 min) and anisomycin treatment, JNK phosphorylation was not changed detectably by $\mathrm{E}_{2}$ (Fig. $2 \mathrm{~B}$, upper and middle panels). The total amounts of ERK (Fig. 2A, lower panel) and JNK (Fig. 2B, lower panel) proteins were not changed by $\mathrm{E}_{2}$. Although $\mathrm{E}_{2}$ did not affect the phosphorylation of p38 under quiescent conditions (0.4\% FBS), $\mathrm{E}_{2}$ induced p38 phosphorylation 

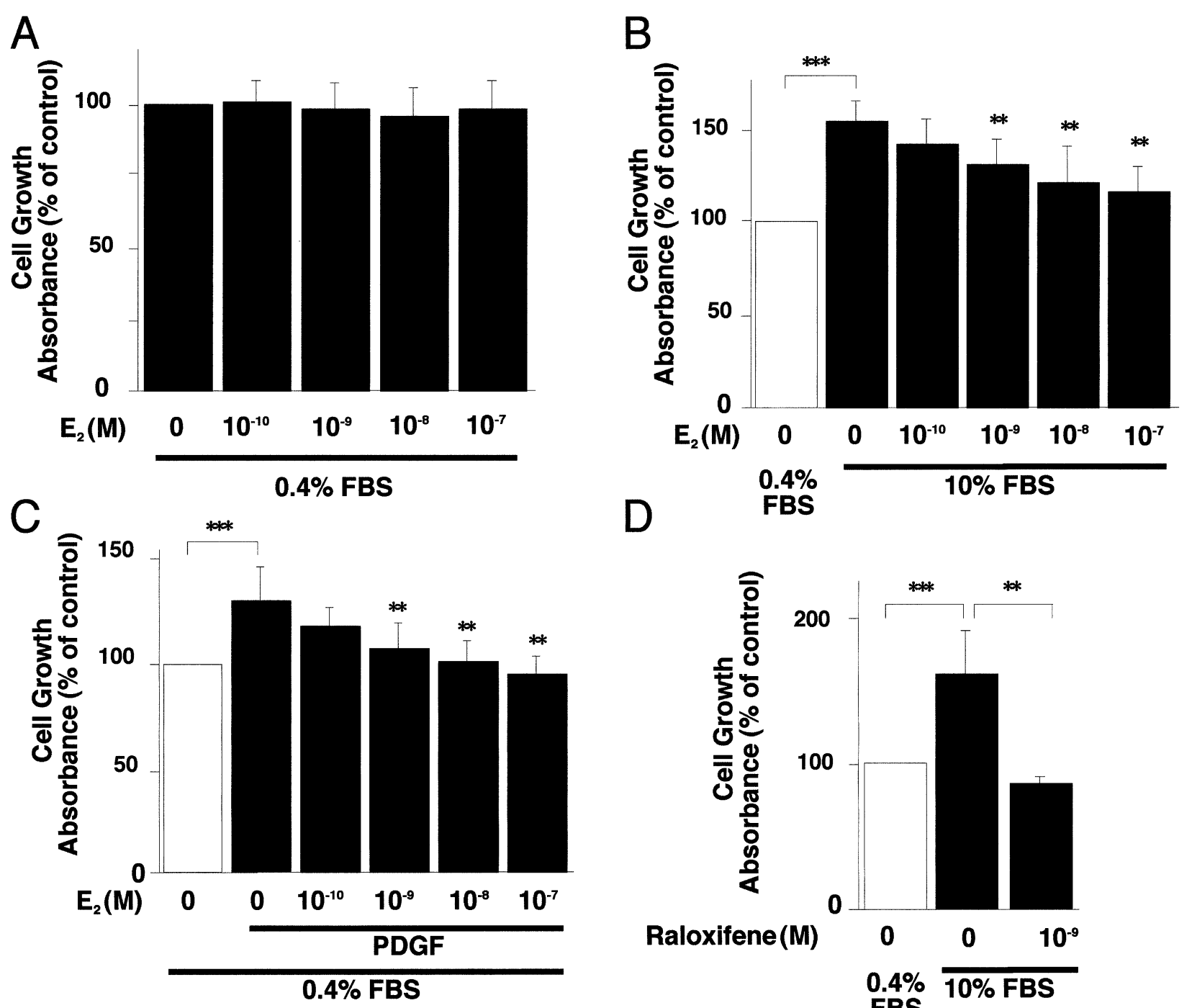

Figure $1 \mathrm{E}_{2}$ and raloxifene inhibit VSMC proliferation induced by $10 \%$ FBS or by PDGF. After starvation, cell growth was promoted by $0 \cdot 4 \%$ FBS (A), 10\% FBS (B and D) or $25 \mathrm{ng} / \mathrm{ml}$ PDGF (C). Growth-promoted cells were treated with various concentrations of $E_{2}(A, B, C)$ or $10^{-9} \mathrm{M}$ raloxifene (D). After $48 \mathrm{~h}$ incubation, cell growth was evaluated by the MTS assay as described in Materials and Methods. Cell growth is expressed as a percentage of the absorbance obtained in the MTS assay in the non-stimulated condition. Data are expressed as means \pm S.E.M. $(n=12)$. ${ }^{* \star} P<0 \cdot 0001$ compared with $0 \cdot 4 \%$ FBS; ${ }^{* *} P<0 \cdot 01$ compared with no treatment with $E_{2}$ or raloxifene.

under growth-stimulated conditions, such as in medium containing 10\% FBS (Fig. 2C). Raloxifene at $10^{-9} \mathrm{M}$ also induced the phosphorylation of p38 (Fig. 2D, upper and middle panels). The total amount of p38 was not changed by $\mathrm{E}_{2}$ (Fig. 2C, lower panel) or raloxifene (Fig. 2D, lower panel).

\section{$E_{2}$-induced phosphorylation and activation of $p 38$}

To evaluate the dose dependency of $\mathrm{E}_{2}$-induced phosphorylation of p38 in VSMC under the growth-stimulated conditions, cells were treated with various concentrations of $E_{2}$ for $10 \mathrm{~min}$. In the range of $10^{-9} \mathrm{M}$ to $10^{-6} \mathrm{M}, \mathrm{E}_{2}$ induced the phosphorylation of $\mathrm{p} 38$ in a dose-dependent manner (Fig. 3A, upper and middle panels). The time course of $\mathrm{E}_{2}$-induced phosphorylation of p38 was also evaluated in VSMC under the growth-stimulated conditions. The increase in the phosphorylation of p38 induced by $10^{-8} \mathrm{M} \mathrm{E}_{2}$ reached a maximum at $10 \mathrm{~min}$ and rapidly declined thereafter (Fig. 3B, upper and middle panels). $E_{2}$ did not change the total amount of $\mathrm{p} 38$ protein (Fig. 3A and 3B, lower panels). 
A
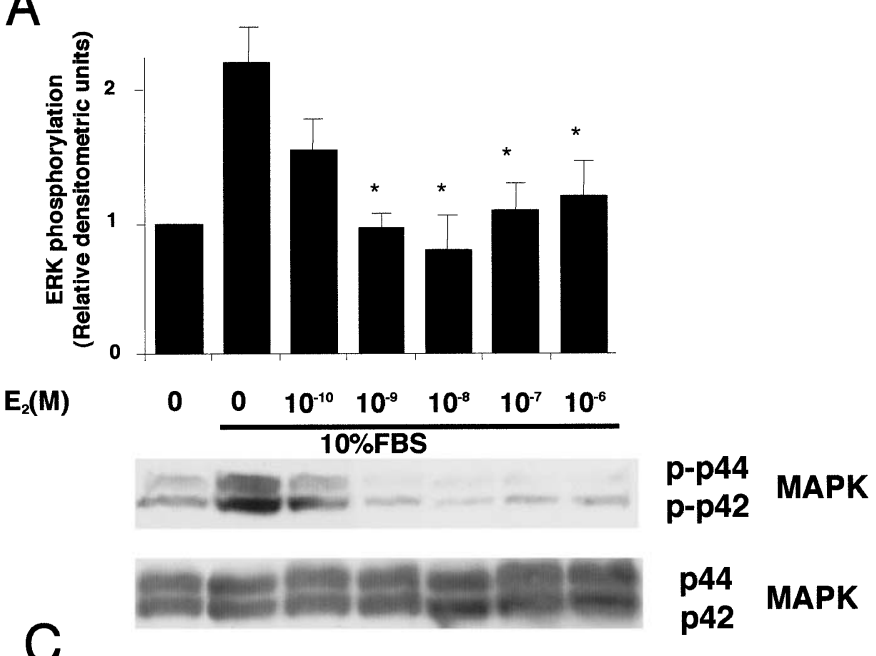

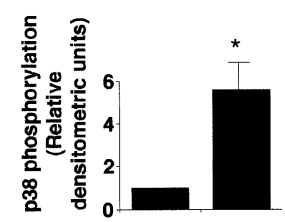

$E_{2} 10^{-8} M$

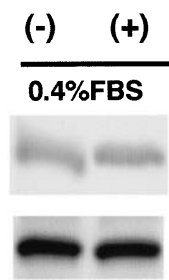

$(-) \quad(+)$

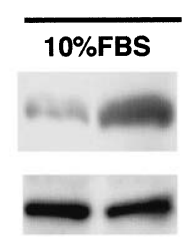

B
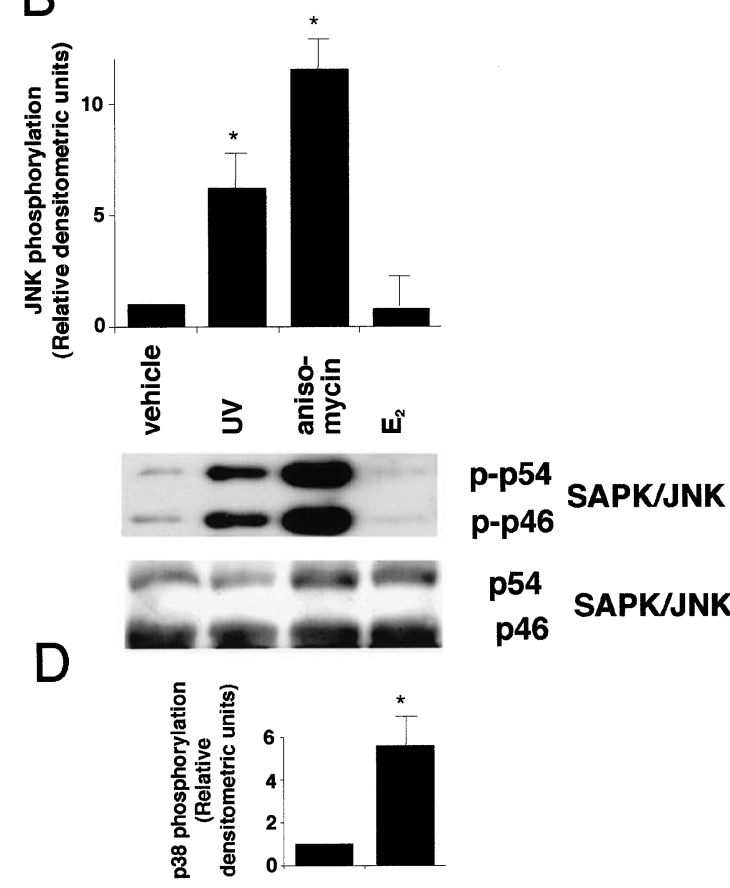

Raloxifene $10^{-9} \mathrm{M}$ p54

p46
SAPK/JNK

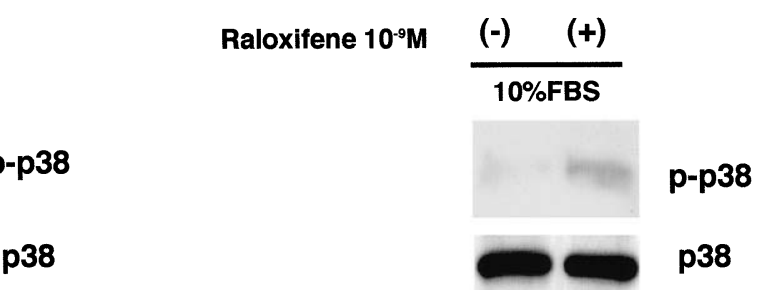

Figure 2 Effect of $E_{2}$ and raloxifene on MAP kinase family members. VSMC were treated for 10 min with the indicated concentrations of $E_{2}$ with $10 \%$ FBS $(A)$, or with UV for $30 \mathrm{~min}, 10^{-6} \mathrm{M}$ anisomycin for $10 \mathrm{~min}$ or $10^{-8} \mathrm{M} \mathrm{E}_{2}$ for $10 \mathrm{~min}$ (B). VSMC were treated for 10 min with or without $10^{-8} \mathrm{M} \mathrm{E}_{2}$ with $0 \cdot 4 \% \mathrm{FBS}$ or $10 \% \mathrm{FBS}(\mathrm{C})$. VSMC were treated for 10 min with or without $10^{-9} \mathrm{M}$ raloxifene with $10 \%$ FBS (D). Equal amounts of protein were analyzed by Western blotting using a specific antibody against phosphorylated ERK1/ERK2 (A, middle panel), phosphorylated JNK (B, middle panel), phosphorylated p38 (p-p38) (C and D, middle panels), or total ERK1/ERK2, JNK, p38 antibody ( $A, B, C$ and $D$, lower panels). Relative densitometric units of the p-ERK (A), p-JNK (B), and p-p38 (C and D) bands are shown in the upper panels, with the density of the control bands set arbitrarily at $1 \cdot 0$. Values shown represent the mean \pm S.E. from at least three separate experiments. Significant differences are indicated: ${ }^{*} P<0 \cdot 01$.

To determine if this response involves ER, the effect of concomitant treatment with the highly specific ER antagonist ICI 182,780 was determined (Fig. 3C). ICI 182,780 completely abolished the induction of p38 phosphorylation by $\mathrm{E}_{2}$. Moreover, the effect of actinomycin $\mathrm{D}$, an inhibitor of gene transcription (Hisamoto et al. 2000) was tested to examine the influence of genomic events mediated by nuclear ERs (Fig. 3D). Although actinomycin $\mathrm{D}$ inhibited the $\mathrm{E}_{2}$-induced transcriptional transactivation of an estrogen-responsive reporter plasmid encoding estrogen response element-thymidine kinaseluciferase in VSMC (data not shown), it did not detectably affect the induction of $\mathrm{p} 38$ activation by $\mathrm{E}_{2}$. This result suggests that the phosphorylation and activation of p38 by $\mathrm{E}_{2}$ mainly depend on non-genomic effects of estrogen via $\mathrm{ER}$. The total amount of p38 was not changed by $\mathrm{E}_{2}$ (Fig. 3C and 3D, lower panels).

Effect of ERa expression on $E_{2}$-induced 338 phosphorylation

Because VSMC express both ER $\alpha$ and ER $\beta$ mRNA (Fig. 4A) as reported previously (Karas et al. 1994), it is not known which estrogen receptor mediates the phosphorylation of p38 in VSMC. The A10 cell line is derived from the thoracic aorta of embryonic rats and is a commonly used model of vascular smooth muscle cells (Weiss et al. 1998). ER $\alpha$ mRNA was not detected by RT-PCR (Fig. 4A) and ER $\alpha$ was not detected by Western blotting (Fig. 4B, lower panel) in A10 cells (Fig. 4A), in agreement with a previous report (Smith et al. 1998). We therefore 

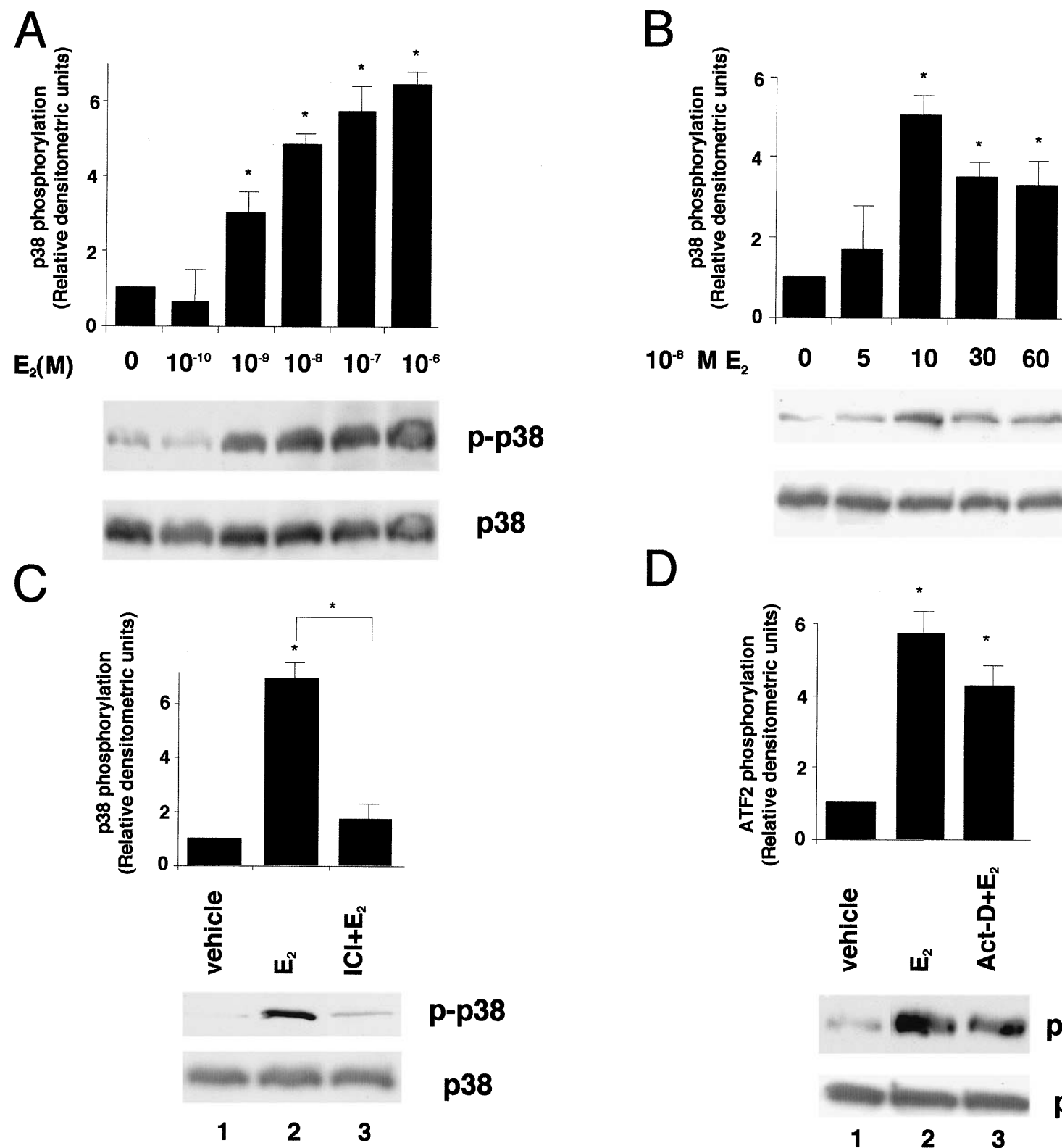

(min)

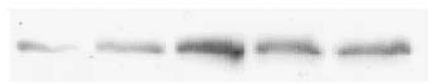

p-p38
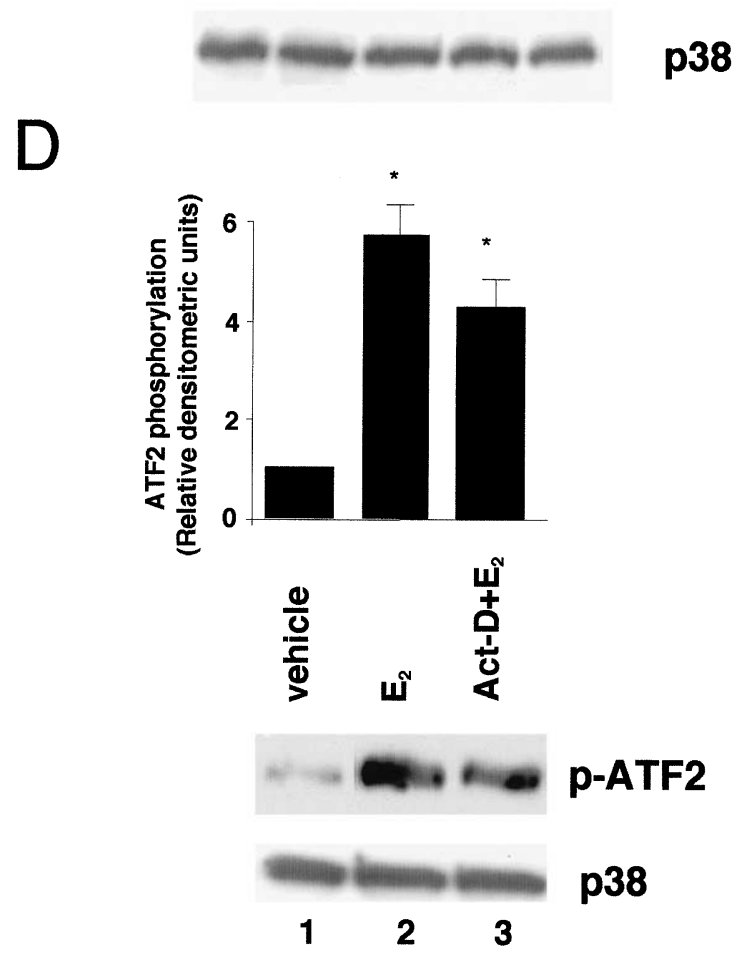

Figure $3 \mathrm{E}_{2}$-induced $\mathrm{p} 38$ phosphorylation and activation. VSMC were treated for 10 min with various concentrations of $E_{2}(A)$, and with $10^{-8} \mathrm{M} \mathrm{E}_{2}$ for the indicated times (B). (C) VSMC were pre-treated with $10^{-6} \mathrm{M} \mathrm{ICl} \mathrm{182,780} \mathrm{(ICl)} \mathrm{for} 30$ min (lane 3), then treated for 10 min with (lanes 2 and 3) or not treated with (lane 1) $10^{-8} \mathrm{M} \mathrm{E}_{2}$. Equal amounts of protein were analyzed by the Western blotting method using a specific antibody against phosphorylated p38 (p-p38) (A, B, and C, middle panels) or total p38 (A, B, C and D, lower panels). (D) VSMC were treated with $10^{-8} \mathrm{ME}_{2}$ with $10 \% \mathrm{FBS}$ for $10 \mathrm{~min}$ (lane 2), or with $25 \mu \mathrm{g} / \mathrm{ml}$ actinomycin D (Act-D) for 120 min, and then treated for $10 \mathrm{~min}$ with $10^{-8} \mathrm{M} \mathrm{E}_{2}$ (lane 3). Lysates were subsequently subjected to immunoprecipitation with immobilized anti-p38 antibody and the kinase reaction was carried out in the presence of GSK-ATF2 fusion protein, followed by Western blotting with an anti-phospho-ATF2 antibody (D, middle panel). Relative densitometric units of the p-p38 (A-C) and p-ATF2 (D) bands are shown in the upper panels, with the density of the control bands set arbitrarily at $1 \cdot 0$. Values shown represent the mean \pm S.E. from at least three separate experiments. Significant differences are indicated: ${ }^{*} P<0 \cdot 01$.

examined the effect of $E_{2}$ on the phosphorylation of $\mathrm{p} 38$ in A10 cells and A10 cells transfected by ER $\alpha$ expression vector. The expression of ER $\alpha$ in A10 cells trasfected with ER $\alpha$ expression vector was confirmed by Western blotting
(Fig. 4B, lower panel). Although $\mathrm{E}_{2}$ had no effect on the p38 phosphorylation in A10 cells, transfection of ER $\alpha$ expression vector caused an increase in $\mathrm{E}_{2}$-induced $\mathrm{p} 38$ phosphorylation (Fig. 4B, upper and middle panels). 
A

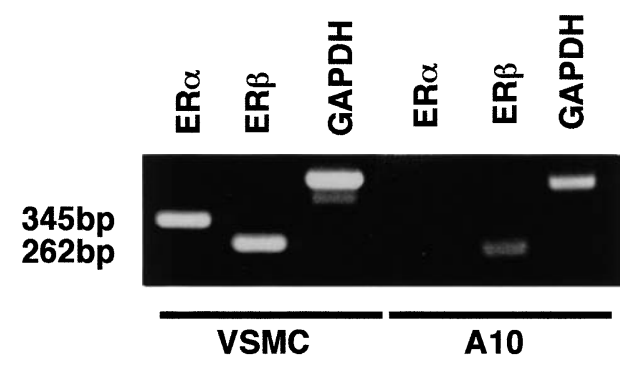

B

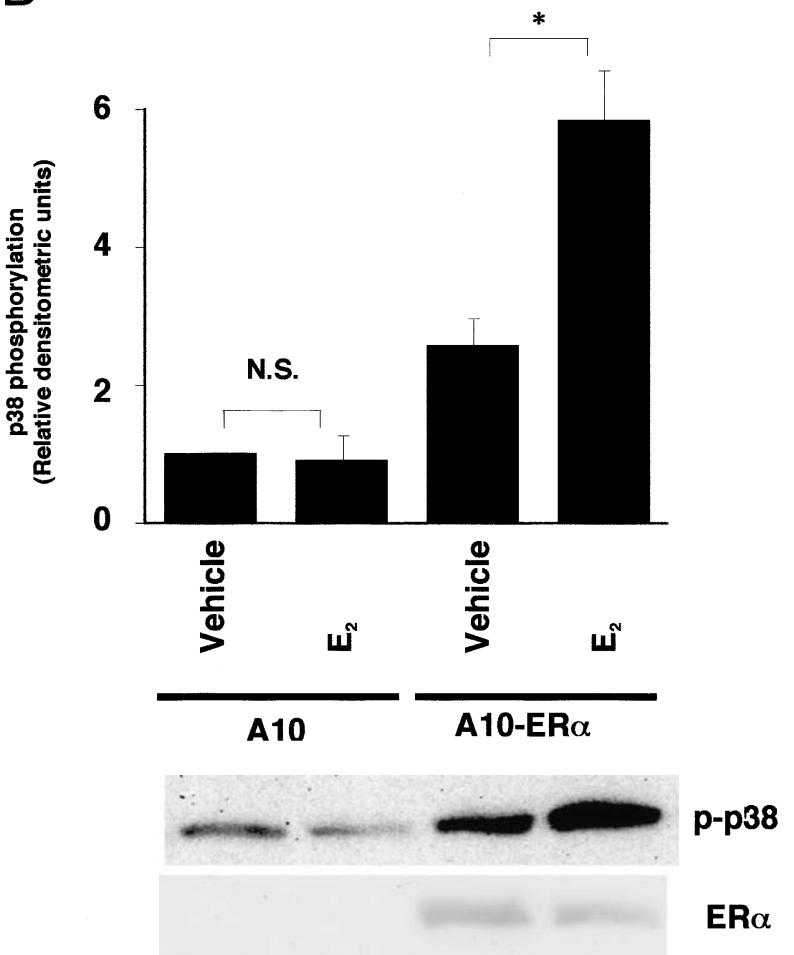

Figure 4 Effect of ER $\alpha$ expression on $E_{2}$-induced $\mathrm{p} 38$ phosphorylation. (A) Total RNA samples were isolated from cultured VSMC and A10 cells. RT-PCR was performed as described in Materials and Methods. Amplification products of 345 and 262 bp correspond to ER $\alpha$ and ER $\beta$ cDNA respectively.

(B) Cells were transfected (lanes 3 and 4) or not transfected (lanes 1 and 2) with ER $\alpha$ expression vector (pCMV-fER), and after $72 \mathrm{~h}$ were treated for 10 min with $10^{-8} \mathrm{ME}_{2}$ with $10 \% \mathrm{FBS}$. Equal amounts of protein were analyzed by Western blotting using a specific antibody against phosphorylated p38 (middle panel) or $\mathrm{ER} \alpha$ (lower panel). Relative densitometric units of the p-p38 bands are shown in the upper panel, with the density of the control bands set arbitrarily at $1 \cdot 0$. Values shown represent the mean \pm S.E. from at least three separate experiments. Significant differences are indicated: ${ }^{\star} P<0 \cdot 01$. N.S., not significant.
These results suggest that $E R \alpha$ is required for the $E_{2}-$ induced p38 phosphorylation.

$\mathrm{E}_{2}$ and raloxifene induce apoptosis in VSMC

The signaling cascade of p38 is known to be involved in cellular processes involving apoptosis (Xia et al. 1995) and to activate apoptosis-related transcription factors such as ATF2 or Elk-1 in many kinds of cells (Schaeffer \& Weber 1999). In addition, it was reported that activation of $\mathrm{p} 38$ by $\mathrm{E}_{2}$ is coupled to ER-induced apoptosis in HeLa cells transfected with ER (Zhang \& Shapiro 2000). Therefore, we next examined whether $\mathrm{E}_{2}$ induces apoptosis in VSMC. VSMC were grown in the presence of 10\% FBS or $25 \mathrm{ng} / \mathrm{ml}$ PDGF-BB with or without $10^{-8} \mathrm{M} \mathrm{E}_{2}$. Cultured cells were stained by the TUNEL method (Gavrieli et al. 1992). Apoptotic cells were stained brown (Fig. 5A), and were counted by inspection under a light microscope. $\mathrm{E}_{2}$ induced apoptosis in VSMC cultured in medium containing 10\% FBS (Fig. 5B) or $25 \mathrm{ng} / \mathrm{ml}$ PDGF-BB (Fig. 5C), while $\mathrm{E}_{2}$ did not induce apoptosis without these growth stimulants $(0 \cdot 4 \%$ FBS) (Fig. $5 \mathrm{~B})$. These data suggest that estrogen induced apoptosis in VSMC only under growth-stimulated conditions. Furthermore, a specific antagonist of ER, ICI 182,780 and a specific inhibitor of p38, SB 203580, significantly inhibited the $\mathrm{E}_{2}$-induced apoptosis (Fig. $5 \mathrm{~B}$ and $5 \mathrm{C}$ ). These data suggest that the signaling cascade of p38 mediates the $\mathrm{E}_{2}$-induced apoptosis of VSMC via a mechanism involving ER.

Moreover, we examined whether raloxifene induces apoptosis in VSMC. TUNEL staining analysis showed that raloxifene at $10^{-9} \mathrm{M}$ induced apoptosis in VSMC cultured in medium containing 10\% FBS (Fig. 5D).

We also performed cell cycle analysis to examine the effects of $E_{2}$ and raloxifene on serum-stimulated cell cycle progression in VSMC. In the presence of $10^{-8} \mathrm{M} \mathrm{E}_{2}$ (Fig. $5 \mathrm{E}$ ) or $10^{-9} \mathrm{M}$ raloxifene (data not shown), the entry of VSMC into $S$ phase from $G_{0} / G_{1}$ phase was partially blocked, while there was a concomitant increase in the percentage of apoptotic cells to a level about fivefold higher than that under non-stimulated conditions, suggesting that $\mathrm{E}_{2}$ induced the cells to undergo apoptosis.

\section{Discussion}

Although recent evidence suggests that direct vascular effects of estrogen play a crucial role in the atheroprotective properties of the hormone (Mendelsohn \& Karas 1999), the mechanisms are not well understood. Smooth muscle cells are the major cellular constituent of the medial layer of the aorta. These cells play a key role in the progression of atherosclerosis. The major finding of the present study is that non-genomic signaling mediates 
A

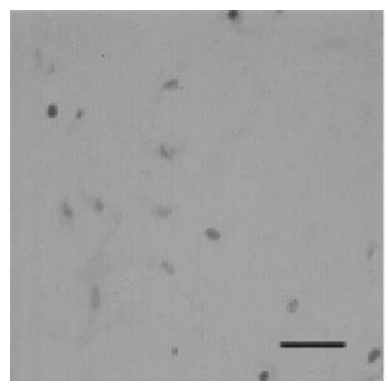

$0.4 \%$ FBS+PDGF

C

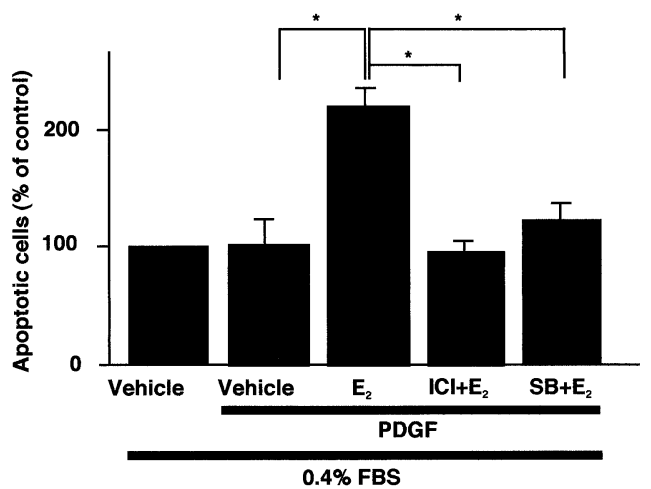

B

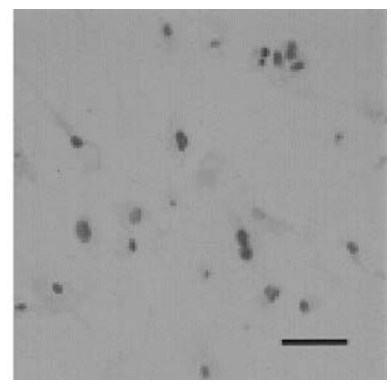

$0.4 \%$ FBS+PDGF+E

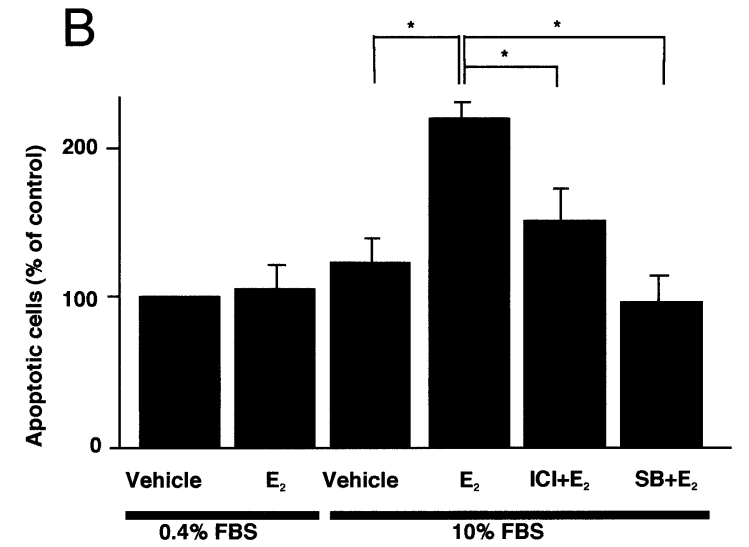

D

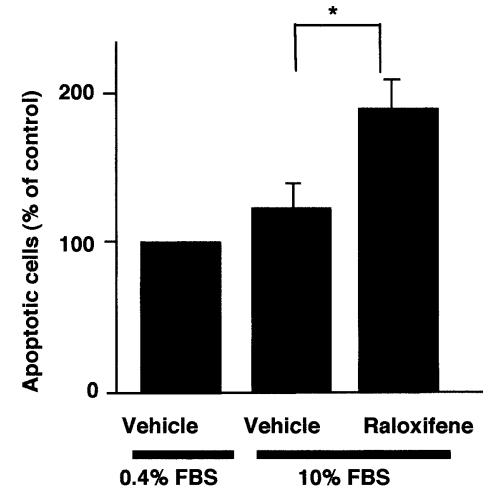

$E$

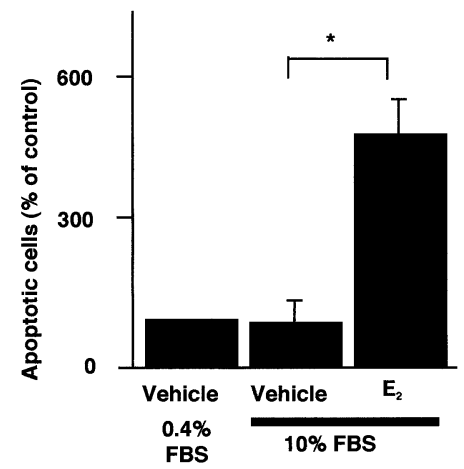

Figure 5 Effects of $E_{2}$ and raloxifene on apoptosis of VSMC. Cells were grown on a chamber slide. (A-C) VSMC were treated for $1 \mathrm{~h}$ with or without $10^{-8} \mathrm{M} \mathrm{E}_{2}$ under quiescent conditions ( $0 \cdot 4 \% \mathrm{FBS}$ ) or growth-stimulated conditions (10\% FBS or $25 \mathrm{ng} / \mathrm{ml} \mathrm{PDGF).} \mathrm{In} \mathrm{some}$ groups, cells were pre-treated with $10^{-6} \mathrm{M} \mathrm{ICl} \mathrm{182,780}$ (ICl) or $10^{-6} \mathrm{M} \mathrm{SB} 203580$ (SB) for $30 \mathrm{~min}$. (D) VSMC were treated for $1 \mathrm{~h}$ with or without $10^{-9} \mathrm{M}$ raloxifene under growth-stimulated conditions (10\% FBS). Cells were stained by the TUNEL method using a kit for detection of apoptosis in situ. (A, left panel) FBS $0 \cdot 4 \%$ with $25 \mathrm{ng} / \mathrm{ml}$ PDGF. (A, right panel) FBS 0.4\% with $25 \mathrm{ng} / \mathrm{ml}$ PDGF and $10^{-8}$ M $E_{2}$. Apoptotic cells were stained and were counted by visual inspection under a light microscope. Methyl green solution $(0 \cdot 5 \%)$ was also used for counterstaining. Magnification: $\times 200$. Bar $=100 \mu \mathrm{m}$. The percentage of apoptotic cells is shown in B, C, and D, with the proportion of apoptotic cells in the cultures treated with vehicle set arbitrarily at $100 \%$. Values shown represent the mean \pm S.E. from five separate experiments. Significant differences are indicated: ${ }^{*} P<0 \cdot 05$. (E) VSMC were growth-stimulated by $10 \%$ FBS or were not stimulated $(0 \cdot 4 \% \mathrm{FBS})$, and were then incubated with or without $\mathrm{E}_{2}$ for $24 \mathrm{~h}$. All cells were subjected to FACS analysis to measure the DNA content. The apoptotic cells included the sub- $G_{0} / G_{1}$ fraction. Values are the mean \pm S.E.M. of three independent experiments. ${ }^{*} P<0.05$ compared with the vehicle.

the estrogen- and raloxifene-induced growth inhibition of human VSMC in the pathologically proliferative state. VSMC grown under proliferative conditions in vitro undergo a change from the contractile to the synthetic phenotype and are considered a model for thickening of the arterial intimal layer as an initiating event of atherosclerosis in vivo (Kindy \& Sonenshein 1986).

MAP kinases have been implicated in the signaling cascades involved in the proliferation and hypertropy of smooth muscle cells (Force \& Bonventre 1998). These kinases include the ERK and the stress-activated MAP kinases, JNK and $\mathrm{p} 38$. One of the mechanisms involved in these effects was previously reported to be inhibition of ERK activity by estrogen in human VSMC (Dubey et al. 2000), which we also confirmed (Fig. 2A). We further explored the signaling cascade that underlies the estrogeninduced inhibition of VSMC proliferation, and found evidence that estrogen rapidly activates the p38 signaling cascade and induces apoptosis via ER in VSMC. Activation of p38 may be an upstream step regulating other proteins involved in cell death signaling (Xia et al. 1995). A specific inhibitor of p38, SB 203580, blocked apoptosis, and a specific antagonist of ER, ICI 182,780, blocked both apoptosis and the induction of p38 phosphorylation by $\mathrm{E}_{2}$ in VSMC. To our knowledge, although there is evidence that docosahexaenoic acid induces apoptosis in rat mesenteric VSMC via the activation of $\mathrm{p} 38$ (Diep et al. 2000), this is the first study showing that $\mathrm{E}_{2}$ induces apoptosis via a p38-dependent mechanism in human VSMC. 
In the present study, we demonstrated that $\mathrm{E}_{2}$ induced apoptosis through a p38 signaling cascade in synthetic VSMC. Although estrogen was reported to have an anti-apoptotic effect in vascular endothelial cells (Razandi et al. 2000), it was reported that estrogen induced apoptosis in an erythroid cell line (Blobel \& Orkin 1996) and induced apoptosis and $G_{1}$ cell cycle arrest of human multiple myeloma cells (Wang et al. 2001). Moreover, $\mathrm{E}_{2}$ stimulates the growth of MCF-7 cells and does not induce p38 phosphorylation or apoptosis, while activation of p38 by $\mathrm{E}_{2}$ is coupled to ER-induced apoptosis in HeLa cells transfected with ER (Zhang \& Shapiro 2000). Thus, the ability of $E_{2}$ to modulate such diverse cell functions appears to be the result of its ability to modulate signaling cascades in a cell- and tissue-specific manner. Hence, the balance among activities of the ERK, the JNK, and the p38 cascades may be an important factor in the decision of different types of cells whether to proliferate, remain quiescent, or undergo apoptosis when they are stimulated by estrogen. Hayashi et al. (1999) reported that a change in the balance between the phosphoinositide 3-kinase (PI3$\mathrm{K}) / \mathrm{Akt}$ cascade and the ERK/p38 MAP kinase cascade could determine the phenotypes of VSMC. In this study, we have shown that $\mathrm{E}_{2}$ affects the balance between the ERK and p38 MAP kinase cascades: $E_{2}$ enhanced p38 phosphorylation and inhibited ERK phosphorylation. Because $\mathrm{E}_{2}$ stimulates the PI3-K/Akt pathway in human vascular endothelial cells (Hisamoto et al. 2000, Simoncini et al. 2000), it might also affect the balance of the $\mathrm{PI} 3-\mathrm{K} /$ Akt pathway in VSMC.

One report suggested that commercially available $\mathrm{E}_{2^{-}}$ BSA did not mimic $\mathrm{E}_{2}$ and is not an appropriate ligand for investigating non-genomic events mediated by a membrane ER (Stevis et al. 1999). However, the $\mathrm{E}_{2}$ effects in the present study were very rapid, and a specific ER antagonist could prevent the signaling. Moreover, actinomycin D, an inhibitor of gene transcription, was also tested to rule out the influence of genomic events mediated by nuclear ER, and it did not affect the activation of p38. Therefore, we believe that the effects of $\mathrm{E}_{2}$ which we observed here mainly depend on non-genomic effects of estrogen mediated by ER.

The two known estrogen receptors, ER $\alpha$ and $\operatorname{ER} \beta$, mediate the effects of estrogen in all target tissues, including blood vessels. Because both are expressed in VSMC (Fig. 4A), it is not known which of them mediates the phosphorylation of p38 in VSMC. We therefore examined the effect of $E_{2}$ in $A 10$ rat aortic smooth muscle cells, which express ER $\beta$ but not ER $\alpha$ (Fig. 4A). Although $\mathrm{E}_{2}$ had no effect on the p38 phosphorylation in A10 cells, transfection of ER $\alpha$ expression vector caused an increase in $\mathrm{E}_{2}$-induced p38 phosphorylation (Fig. 4B, upper panel). These results suggest that ER $\alpha$ is involved in the induction of p38 phosphorylation by $E_{2}$ in VSMC. Recently, it was reported that VSMC isolated from ER $\beta$-deficient mice showed multiple abnormalities of ion channel function (Zhu et al. 2002). Thus, the function mediated by ER $\alpha$ might be different from that mediated by ER $\beta$ in VSMC. In addition, Karas et al. (2001) showed that $E_{2}$ did not inhibit an increase in the vascular medial area following injury in $\mathrm{ER} \alpha, \beta$ (double) knockout mice, but did inhibit VSMC proliferation of injured carotid arteries in ER $\alpha, \beta$ (double) knockout mice. Therefore, it is possible that there are other receptor-independent mechanisms or unidentified receptor(s) for estrogen.

We conclude that $\mathrm{E}_{2}$ and raloxifene inhibit the proliferation of VSMC by increasing apoptosis induced by $\mathrm{p} 38$ activation, and by reducing ERK MAP kinase activity under growth-stimulating conditions. These effects of $\mathrm{E}_{2}$ and raloxifene on VSMC may mainly depend on nongenomic effects mediated by ER, although the participation of other mechanisms cannot be ruled out. This effect on VSMC may partly account for the antithickening effect of $E_{2}$ on the arterial intimal layer. Moreover, our data support the possibility that raloxifene has favorable effects on vasculature (Barrett-Connor et al. 2002). Since $E_{2}$ induces apoptosis and $G_{1}$ cell cycle arrest in human multiple myeloma cells (Wang et al. 2001) and apolipoprotein E inhibits the PDGF-induced proliferation of VSMC by suppressing cyclin D1 expression (Ishigami et al. 1998), it is possible that $E_{2}$ affects the cell cycle in synthetic VSMC. This possibility is currently under investigation.

\section{References}

Barrett-Connor E, Grady D, Sashegyi A, Anderson PW, Cox DA, Hoszowski K, Rautaharju P, Harper KD \& the MORE investigators (Multiple Outcome of Raloxifene Evaluation) 2002 Raloxifene and cardiovascular events in osteoporotic postmenopausal women: four-year results from the MORE randomized trial. Journal of the American Medical Association 287 847-857.

Blobel GA \& Orkin SH 1996 Estrogen-induced apoptosis by inhibition of the erythroid transcription factor GATA-1. Molecular and Cellular Biology 16 1687-1694.

Diep QN, Touyz RM \& Schiffrin EL 2000 Docosahexaenoic acid, a peroxisome proliferator-activated receptor- $\alpha$ ligand, induces apoptosis in vascular smooth muscle cells by stimulation of p38 mitogen-activated protein kinase. Hypertension 36 851-855.

Dubey RK, Jackson EK, Gillespie DG, Zacharia LC, Imthurn B \& Keller PJ 2000 Clinically used estrogens differentially inhibit human aortic smooth muscle cell growth and mitogen-activated protein kinase activity. Arteriosclerosis, Thrombosis and Vascular Biology 20 964-972.

Falkenstein E \& Wehling M 2000 Nongenomically initiated steroid actions. European Journal of Clinical Investigation 30 (Suppl 3) 51-54.

Force T \& Bonventre JV 1998 Growth factors and mitogen-activated protein kinases. Hypertension 31 152-161.

Gavrieli Y, Sherman Y \& Ben-Sasson SA 1992 Identification of programmed cell death in situ via specific labeling of nuclear DNA fragmentation. Journal of Cell Biology 119 493-501.

Hayakawa J, Ohmichi M, Kurachi H, Kanda Y, Hisamoto K, Nishio Y, Adachi K, Tasaka K, Kanzaki T \& Murata Y 2000 Inhibition of BAD phosphorylation either at serine 112 via extracellular signalregulated protein kinase cascade or at serine 136 via Akt cascade 
sensitizes human ovarian cancer cells to cisplatin. Cancer Research $\mathbf{6 0}$ 5988-5994.

Hayashi K, Takahashi M, Kimura K, Nishida W, Saga H \& Sobue K 1999 Changes in the balance of phosphoinositide 3-kinase/protein kinase $\mathrm{B}(\mathrm{Akt})$ and the mitogen-activated protein kinases (ERK/ p38 MAPK) determine a phenotype of visceral and vascular smooth muscle cells. Journal of Cell Biology 145 727-740.

Hisamoto K, Ohmichi M, Kurachi H, Hayakawa J, Kanda Y, Nishio Y, Adachi K, Tasaka K, Miyoshi E, Fujikawa N, Taniguchi N \& Murata Y 2000 Estrogen induces the Akt-dependent activation of endothelial nitric oxide synthase in vascular endothelial cells. Journal of Biological Chemistry 276 3459-3467.

Ishigami M, Swertfeger DK, Granholm NA \& Hui DY 1998 Apolipoprotein E inhibits platelet-derived growth factor-induced vascular smooth muscle cell migration and proliferation by suppressing signal transduction and preventing cell entry to $G_{1}$ phase. Journal of Biological Chemistry 273 20156-20161.

Karas RH, Patterson BL \& Mendelsohn ME 1994 Human vascular smooth muscle cells contain functional estrogen receptor. Circulation 89 1943-1950.

Karas RH, Schulten H, Pare G, Aronovitz MJ, Ohlsson C, Gustafsson J \& Mendelsohn ME 2001 Effects of estrogen on the vascular injury response in estrogen receptor $\alpha, \beta$ (double) knockout mice. Circulation Research 89 534-539.

Kindy MS \& Sonenshein GE 1986 Regulation of oncogene expression in cultured aortic smooth muscle cells. Post-transcriptional control of c-myc mRNA. Journal of Biological Chemistry 261 12865-12868.

Mendelsohn ME \& Karas RH 1999 The protective effects of estrogen on the cardiovascular system. New England Journal of Medicine $\mathbf{3 4 0}$ 1801-1811.

Nilsson J, Sjolund M, Palmberg L, Thyberg J \& Heldin CH 1985 Arterial smooth muscle cells in primary culture produce a plateletderived growth factor-like protein. PNAS 82 4418-4422.

Pietras RJ \& Szego CM 1977 Specific binding sites for oestrogen at the outer surfaces of isolated endometrial cells. Nature 265 69-72.

Razandi M, Pedram A \& Levin ER 2000 Estrogen signals to the preservation of endothelial cell form and function. Journal of Biological Chemistry 275 38540-38546.

Ross R \& Glomset JA 1973 Atherosclerosis and the arterial smooth muscle cell: proliferation of smooth muscle is a key event in the genesis of the lesions of atherosclerosis. Science 180 1332-1339.

Schaeffer HJ \& Weber MJ 1999 Mitogen-activated protein kinase: specific messages from ubiquitous messengers. Molecular and Cellular Biology 19 2435-2444.

Simoncini T, Hafezi-Moghadam A, Brazil DP, Ley K, Chin WW \& Liao JK 2000 Interaction of oestrogen receptor with the regulatory subunit of phosphatidylinositol-3-OH kinase. Nature 407 538-541.

Smith AF, Bigsby RM, Word RA \& Herring BP 1998 A 310-bp minimal promoter mediates smooth muscle cell-specific expression of telokin. American Journal of Physiology 274 C1188-C1195.

Stampfer MJ, Colditz GA, Willett WC, Manson JE, Rosner B, Speizer FE \& Hennekens CH 1991 Postmenopausal estrogen therapy and cardiovascular disease. Ten-year follow-up from the nurse's health study. New England Journal of Medicine 325 756-762.

Stevis PE, Deecher DC, Suhadolnik L, Mallis LM \& Frail DE 1999 Differential effects of estradiol and estradiol-BSA conjugates. Endocrinology 140 5455-5458.

Truss M \& Beato M 1993 Steroid hormones receptors: interaction with deoxyribonucleic acid and transcription factors. Endocrine Reviews 14 459-479.

Wakatsuki A, Okatani Y, Ikenoue N \& Fukaya T 2001 Effect of medroxyprogesterone acetate on endothelium-dependent vasodilation in postmenopausal women receiving estrogen. Circulation 104 1773-1778.

Wang LH, Yang XY, Mihalic K, Xiao W, Li D \& Farrar WL 2001 Activation of estrogen receptor blocks interleukin-6-inducible cell growth of human multiple myeloma involving molecular cross-talk between estrogen receptor and STAT3 mediated by co-regulator PIAS3. Journal of Biological Chemistry 276 31839-31844.

Weiss RH, Maga EA \& Ramirez A 1998 MEK inhibition augments Raf activity, but has variable effects on mitogenesis, in vascular smooth muscle cells. American Journal of Physiology 274 C1521-C1529.

Writing Group for the Women's Health Initiative Investigators 2002 Risks and benefits of estrogen plus progestin in healthy postmenopausal women: principal results from the Women's Health Initiative randomized controlled trial. Journal of the American Medical Association 288 321-333.

Xia Z, Dickens M, Raingeaud J, Davis RJ \& Greenberg ME 1995 Opposing effects of ERK and JNK-p38 MAP kinases on apoptosis. Science 270 1326-1331.

Zhang CC \& Shapiro DJ 2000 Activation of the p38 mitogenactivated protein kinase pathway by estrogen or by $4-$ hydroxytamoxifen is coupled to estrogen receptor-induced apoptosis. Journal of Biological Chemistry 275 479-486.

Zhang CC, Krieg S \& Shapiro DJ 1999 HMG-1 stimulates estrogen response element binding by estrogen receptor from stably transfected HeLa cells. Molecular Endocrinology 13 632-643.

Zhu Y, Bian Z, Lu P, Karas RH, Bao L, Cox D, Hodgin J, Philip W, Thoren P, Smithies O, Gustafsson J-A \& Mendelsohn ME 2002 Abnormal vascular function and hypertension in mice deficient in estrogen recepor $\beta$. Science 295 505-508.

Received in final form 20 May 2003

Accepted 12 June 2003 